 \\ A pós-graduação em história: tendências e perspectivas da área
}

\author{
Graduate studies in history: \\ trends and prospects for the area
}

\section{Carlos Fico}

Professor, Instituto de Filosofia e Ciências Sociais/Universidade Federal do Rio de Janeiro; coordenador, Área de História/ Coordenação de Aperfeiçoamento de Pessoal de Nível Superior. Largo São Francisco de Paula, 1 20051-070 - Rio de Janeiro - RJ - Brasil

carlos_fico@uol.com.br
FICO, Carlos. A pós-graduação em história: tendências e perspectivas da área. História, Ciências, Saúde - Manguinhos, Rio de Janeiro, v.22, n.3, jul.-set. 2015, p.1019-1031.

\section{Resumo}

Historiador e coordenador da área de história na Coordenação de Aperfeiçoamento de Pessoal de Nível Superior (Capes), Carlos Fico discorre sobre os critérios e desafios da avaliação enfrentados pela Fundação Capes e analisa o panorama do campo. Faz críticas ao produtivismo acadêmico, trata de distorções na formação do historiador, do dilema sobre o perfil esperado do mestrado acadêmico e comenta os esforços de internacionalização da disciplina. Defende maior maturidade da área em termos de reconhecimento e atendimento das demandas sociais, bem como o aperfeiçoamento de procedimentos internos da área, como a avaliação por pares.

Palavras-chave: Coordenação de Aperfeiçoamento de Pessoal de Nível Superior (Capes); historiografia; avaliação da área de história; pósgraduação; internacionalização.

\section{Abstract}

Historian and coordinator of the history area in Coordenação de Aperfeiçoamento de Pessoal de Nivel Superior (Capes), Carlos Fico discusses the criteria and challenges of evaluation faced by Fundação Capes and analyzes the panorama of the field. He criticizes academic productivism, deals with the distortions in the training of the historian, the dilemma with respect to the expected profile of the academic master and comments on the internationalization efforts of the subject. He advocates greater maturity of the area in terms of acknowledging and meeting social demands, as well as enhancing internal procedures in the area, such as peer review.

Keywords: Coordenação de Aperfeiçoamento de Pessoal de Nível Superior (Capes); historiography; evaluation of the history area; graduate studies; internationalization. 
É uma satisfação fazer esta apresentação no programa de pós-graduação da Casa de Oswaldo Cruz. ${ }^{1}$ Por razões familiares tenho afinidades com o tema da história da saúde e das ciências, embora não o pesquise. Minha mãe era sanitarista e me lembro bem das campanhas de vacinação contra tuberculose que eram promovidas aqui no Rio de Janeiro. Eu devia ter uns seis, sete anos e ficava acompanhando aquela loucura.

Vocês talvez não saibam, mas comecei minha carreira acadêmica pesquisando a historiografia brasileira. Candidatei-me ao cargo de coordenador da área em grande medida por conta dos trabalhos que fiz nos anos 1980, de avaliação da historiografia brasileira, com Ronald Polito, com quem criei o Centro Nacional de Referência Historiográfica [CNRH] na Universidade Federal de Ouro Preto. Naquela ocasião Ronald e eu percebemos a importância dos programas de pós-graduação para a profissionalização da área de história. Isso nos levou a mapear toda produção brasileira da área e despertou meu interesse por continuar acompanhando-a. Eu achava que podia contribuir como coordenador da área.

Queria muito estar nesse cargo para aprimorar os procedimentos de avaliação, pelos quais algumas vezes somos acusados de produtivismo, mas que se pautam muito mais por princípios éticos e profissionais de equanimidade, justiça, transparência e de superação de tradicionalismos da nossa área. Mesmo tendo de enfrentar as animosidades decorrentes do equacionamento de algumas injustiças, como programas tradicionais com notas supervalorizadas ou o inverso, programas de qualidade, como é o caso do programa da Casa de Oswaldo Cruz, com notas baixas.

Meu objetivo aqui é abordar brevemente a questão da avaliação propriamente dita e trazer algumas impressões de natureza teórica e historiográfica sobre a área. Muitas dessas considerações sobre a área são bastante negativas, mas isso evidentemente não tem significado para a avaliação da Capes, ainda que minhas visões como historiador e coordenador da área se combinem na função em que me encontro no momento.

Há tempos que a historiadora Raquel Glezer e eu queríamos fazer uma avaliação propriamente historiográfica da área de história, que praticava uma avaliação muito impressionista. A consolidação de critérios forneceu-nos um retrato mais objetivo. Uma das vantagens dessa avaliação mais objetiva por nós implementada é a de permitir um mapeamento, possibilitando não só considerar o perfil dessa produção em termos historiográficos, mas também planejar estratégias.

Um aspecto substantivo e, a meu ver, evidente é que as comunidades nacionais de historiadores que realmente se consolidam (estou pensando aqui na francesa, na norteamericana, na inglesa e em algumas poucas outras) "atrevem-se" a praticar uma história que não é só a de seus países. De maneira que temos pensado em propor à Capes um programa global de fomento à história não brasileira. Muitos logo se queixaram, temendo que não tivéssemos mais recursos para pesquisar a história do Brasil. Mas é evidente que já temos constituída uma comunidade nacional de pesquisadores robusta e qualificada para praticar a história das nações africanas, da América Latina, dos EUA, a história antiga, medieval e

\footnotetext{
${ }^{1}$ Este artigo originou-se de apresentação realizada no Programa de Pós-graduação em História das Ciências e da Saúde (PPGHCS) da Casa de Oswaldo Cruz/Fiocruz, no dia 10 de junho de 2014. As perguntas que o complementam foram feitas pelos presentes ao evento: docentes e discentes do PPGHCS e público em geral.
} 
moderna. É um salto qualitativo muito grande se nos dedicarmos a dominar a historiografia que não se restringe ao Brasil. Tenho o projeto, caso seja reconduzido à coordenação da área, de fomentar a pesquisa em história não brasileira que é produzida por algumas comunidades bem qualificadas. Hoje a área de história está consolidada nacionalmente. Abandonou nos últimos tempos a prática da reclamação obtusa e persistente, por meio da qual afirmava certa marginalidade e sustentava junto à Capes um perfil que seria distinto das áreas tecnológicas e das ciências da vida, sobretudo em termos de publicações. Isso só nos desqualificava. Em vez de um apoio diferenciado, a reação que obtínhamos era as outras 47 áreas nos dizendo: "mas vocês não têm critérios objetivos de avaliação?"

A implementação desses critérios, portanto, foi fundamental para conferir mais respeitabilidade à área, que, aliás, passou a compor o Conselho Técnico-científico da Capes. Tal respeitabilidade se expressa também na qualidade e quantidade da produção, que dão margem a saltos ousados, como a maior abertura para temas fundamentais que não estão no âmbito estrito da história do Brasil, mas que se relacionam profundamente com ela ou que estão na agenda contemporânea, como a história da China. São possibilidades que devem ser expressas em propostas. Nós é que definimos para a Capes como deve ser a avaliação da área de história, e para isso é preciso que ela se torne respeitada e com propostas ousadas e inovadoras que a qualifiquem diante das demais. Até porque a avaliação é mais do que a atribuição de notas a programas; é também uma disputa orçamentária.

Um dos problemas atuais da nossa área diz respeito à proliferação de cursos de mestrado nos últimos dez, 15 anos. Na sua origem mais remota, nos anos 1970-1980, a área se configurou a partir de uma espécie de reserva de mercado prejudicial ao campo da história, porque reservou para o eixo Rio-São Paulo a incumbência de pesquisar história geral - seja lá o que for essa quimera - reservando aos programas criados fora desse eixo a incumbência de dedicar-se à história local. Dessa forma, tivemos e ainda temos uma grande produção de teses e dissertações que Francisco Iglesias chamava de paroquialista, ou seja, marcada por fortíssimo empirismo e que se legitima exclusivamente por estar ligada ao local. É uma limitação, sobretudo para os cursos mais recentes de mestrado, alguns com produção de baixa densidade teórica e historiográfica. Esse é o tipo de ponderação que faço como analista da historiografia e que não traz impactos na avaliação da Capes. Temos em diversos programas uma produção historiográfica extremamente qualificada, mas que convive com uma massa ainda significativa de trabalhos com menor profundidade historiográfica e teórica, sobretudo aqueles vinculados a perspectivas chamadas equivocadamente de regionais, mas que, na verdade, são localistas. A história regional é uma sobreposição das categorias teóricas de tempo e espaço, mas não é assim que ela é praticada em geral.

Outra limitação tem a ver com certo tradicionalismo da nossa área, manifestado, por exemplo, numa resistência à interdisciplinaridade. Se pensarmos em todas as vertentes importantes da história ao longo do século XX, desde a história das mentalidades "original" dos fundadores dos Annales até as modalidades de história praticadas depois dos anos 1980, 1990 como a chamada nouvelle histoire, a história da cultura etc., notaremos que sempre houve uma ligação profunda com outras disciplinas, com a psicologia no início do século, com a sociologia e economia no contexto dos Annales, com a geografia e a antropologia a partir dos anos 1980. De maneira que não é exatamente uma novidade para a história estar associada 
a outras disciplinas. Mas a interdisciplinaridade em termos propriamente epistemológicos ainda é pouco praticada. Alguns programas estão investindo mais nisso.

Temos tentado induzir a interdisciplinaridade. Até a última avaliação trienal da Capes, por exemplo, o corpo docente era avaliado, entre outros critérios, pela titulação, ou seja, tinha de haver um percentual de pesquisadores e professores do programa titulados em história. Nunca tinha percebido o quanto isso é limitante. O professor tem de ter produção correspondente ao escopo do programa, portanto em história, não importa em que ele seja formado.

Ainda em termos de tendências e perspectivas, eu diria que há algo muito curioso na nossa área: existem programas tradicionais, já antigos, que têm pretensão de absorver toda e qualquer perspectiva de pesquisa, da história antiga até a história do tempo presente, e programas mais novos, que se constituíram com áreas de concentração e linhas de pesquisa muito especializadas e que desde seu nascimento se tornam praticamente referências nacionais e até internacionais no seu campo. Isso já é produto da avaliação da área feita pela Capes. Nosso fórum de coordenadores vem discutindo a questão das linhas de pesquisa e das áreas de concentração. Vários grupos novos propõem hoje em dia áreas de concentração recortadas porque percebem que temos abrangência suficiente em termos de mestrado, de modo que é preciso que os programas recém-surgidos apresentem alguma singularidade. Eu citaria dois exemplos de casos bem-sucedidos: os das universidades federais do Pará e de Alfenas. Na Universidade Federal do Pará uma equipe enxuta, muito boa, propôs a criação de um programa em história social da Amazônia, com grande apoio da universidade e pessoal qualificado que já tinha produção nessa linha. Eles logo conseguiram criar o doutorado e rapidamente progrediram da nota quatro para a cinco, tornando-se o primeiro programa com essa pontuação no norte do Brasil. Isso porque têm excelente produção e inserção internacional, pois já se tornaram referência em história social da Amazônia.

Vejam o caso de Alfenas. Eles propuseram um mestrado profissional voltado para o ensino de história ibérica. Um grupo de pesquisadores nesse campo identificou que nossos professores da educação básica não tinham formação adequada em história ibérica, não obstante a importância dessa especialidade para a história do Brasil. Quer dizer, quem quiser se especializar profissionalmente no Brasil em história ibérica vai ter de ir para lá.

Logo, a criação inteligente de áreas de concentração e nichos de pesquisa que não sejam generalistas é uma tendência forte na nossa área. E que difere evidentemente do perfil da área décadas atrás. Nos anos 1970, início dos 1980, era realmente necessário possuir programas mais abrangentes. O programa ao qual pertenço, de história social da UFRJ, abrange tudo. Essa indefinição hoje representa uma crise. Linhas de pesquisa muito generalistas não apresentam significado algum e coexistem com grupos efetivamente dinâmicos que estudam temas como escravidão, história ambiental, ditadura militar. A questão é como essas agendas específicas se inserem nesse formato generalista que no passado fazia algum sentido, mas que hoje representa uma crise frente a essa demanda de especialização.

Alguns programas de pós-graduação não têm aproveitado a potencialidade dessas especificidades: contam com abordagens metodológicas ou "especialidades" em suas áreas de concentração, mas pesquisam de tudo. Portanto, a escolha de áreas de concentração e linhas de pesquisa é absolutamente estratégica para a configuração de um programa ou de um núcleo de pesquisadores como referência na área. 
Os exemplos do Pará e de Alfenas são de programas com abordagens que favorecem a inovação, palavra tão cara às áreas tecnológicas e das ciências da vida. Mas nós também temos de pensar em inovações, em formas de renovação da produção de conhecimento histórico relevante. Nesse sentido, eu chamaria a atenção para outra perspectiva que se refere ao que alguns países chamam de história pública - a percepção da demanda social pela história. Ronald Polito e eu fizemos um levantamento, em nossas pesquisas nos anos 1980 e 1990, nos cadernos especiais de jornais e revistas semanais de grande circulação no Brasil e vimos que, depois da astrofísica e da astronomia, a história é o tema mais publicado. Isto é evidência de uma demanda social com a qual não lidamos. Há várias modificações do campo histórico dos anos 1980-1990 para cá que nem sempre foram atendidas pela comunidade de historiadores, que pratica uma história muito rotineira, sem conexão com uma série de expectativas que demandam o conhecimento histórico.

Finalmente, nós temos no Brasil, há alguns anos, revistas de divulgação para o grande público, mas que em geral são vistas pelos nossos programas de pós-graduação como coisa menor. Essa preocupação com o que chamo aqui de história pública refere-se também a uma dimensão mais formadora, quando pensamos no ensino, nos milhares de alunos que saem das licenciaturas, atuam na educação básica e ficam desassistidos. Isso foi o que nos levou a propor o ProfHistória, uma rede nacional de mestrados profissionais voltados para a qualificação continuada do professor de educação básica. No início houve muita resistência, mas conseguimos aprovar. Vai ter um impacto grande, porque vamos fazer editais anuais para a criação de novos polos do programa. Ou nós oferecemos uma oportunidade de qualificação para aquele professor ou ele vai continuar como está até o fim. Podemos ter a ilusão de que nossas licenciaturas daqui para frente vão formar professores maravilhosos, mas existe um contingente enorme que está e continuará atuando na realidade da sala de aula.

O resultado é que, enquanto exercemos teoricamente muito bem a história nas nossas teses e dissertações, vamos mal na nossa realidade profissional não estritamente acadêmica. Esse comprometimento com a realidade também se expressa na avaliação: ela se preocupa com a produção de conhecimento significativo para a sociedade e com a titulação de mestres e doutores de alto nível. Nesse sentido, parece-me essencial a intervenção mais direta na esfera pública, tendência também observada em programas que se associam às secretarias de educação, entidades do patrimônio público, arquivos, museus, e que amplia o mercado de trabalho para nossos formandos. Há muitas oportunidades de trabalho além do mundo universitário, de modo que é preciso que nossos programas formem pessoas aptas a atuar também nessas outras áreas. Para isso precisamos romper com preconceitos. Até recentemente, quem se formava em história e não queria seguir carreira acadêmica não encontrava nenhuma opção de qualificação continuada, que passaram a ter com os mestrados profissionais.

Há questões concernentes aos nossos cursos universitários de história ainda não atendidas pelos programas de pós-graduação e que também decorrem do modelo implantado pela Capes. Uma delas é o que a professora de história da Unicamp [Universidade Estadual de Campinas] e minha antecessora, Maria Stella Bresciani, chamava de taylorização e especialização precoce. É o famoso aluno profissional em bolsa, que começa a pesquisar na graduação, passa para o mestrado e vai para o doutorado estudando sempre o mesmo tema. Ao fazer um concurso público, é reprovado, porque não sabe dar aula, nunca deu aula e não tem familiaridade 
com outras temáticas da historiografia que não a sua. A nossa área demanda erudição. Sabemos como é importante a formação, leitura e conhecimento de outras áreas para dar uma boa aula. Esse é um desafio enorme. Temos que formar pesquisadores qualificados, especialistas, mas são essas mesmas pessoas que, em geral, vão atuar no ensino universitário de história.

Outro ponto importante é que conseguimos romper com o limite de 24 meses para a dissertação de mestrado, que tem papel importante na formação. Hoje 36 meses é considerado um bom prazo. Mas, além disso, precisamos investir mais na formação do aluno, sobretudo do doutor que pretende ser professor universitário. Então, nós temos responsabilidades que são de

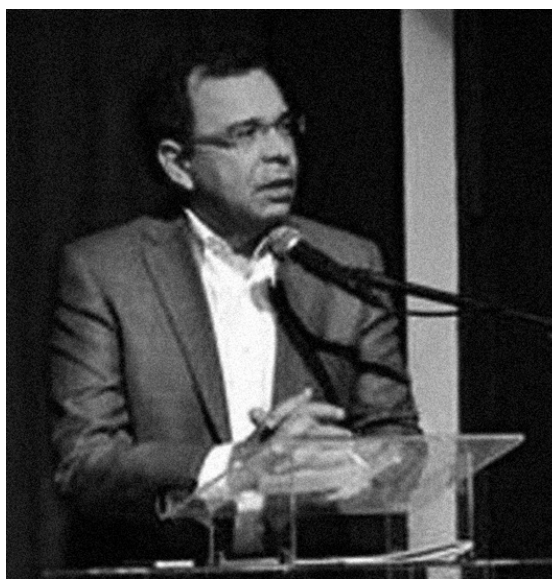
natureza social, que evidentemente têm a ver com nossa atividade de formação na pós-graduação, mas que extrapolam a simples produção de teses acadêmicas. São aspectos que não estão totalmente claros para nossa área. Eles envolvem a valorização de itens como material didático e produção técnica, que ainda não sabemos como considerar na avaliação.

Nós temos uma cobertura quase nacional de programas de pós-graduação em todas as unidades da federação. As visitas que faço aos programas foram fundamentais para perceber que a qualidade não está mais circunscrita ao eixo Rio-São Paulo. Vivemos uma fase de muita heterogeneidade e mudança. Não só no Brasil, mas em toda a produção historiográfica ocidental, ainda sofremos o rescaldo da chamada crise da história dos anos 1980-1990, com várias repercussões, inclusive um forte empirismo. Acho que temos de perceber essas sinalizações da contemporaneidade e as demandas sociais e políticas para nossa área, tentando aproveitá-las melhor, de maneira propositiva. Devemos apresentá-las para as agências de fomento - não só a Capes, mas também o CNPq [Conselho Nacional de Desenvolvimento Científico e Tecnológico] - fazendo propostas que correspondam a essa consolidação e a essa percepção, sobretudo reconhecendo a importância da qualificação crítica dos nossos professores universitários e da educação básica.

Uma tendência, mas também uma possibilidade muito concreta é a da atuação interinstitucional. Por exemplo, programas de doutorado temáticos envolvendo várias instituições. Outra é de integração de periódicos, tentando reduzir essa pulverização enorme de revistas na nossa área.

Enfim, meu objetivo aqui foi dar a vocês as minhas impressões. Como disse, elas não têm implicação direta na avaliação, mas certamente o fato de termos uma avaliação mais objetiva e consolidada, que confere um retrato claro da área, permite aprimorar uma reflexão mais abrangente sobre nossa disciplina no cenário brasileiro. 
Queria que falasse um pouco mais sobre a internacionalização de nossa produção historiográfica. Trabalhos reconhecidos como produções notáveis em nossa área têm repercussão internacional, mas esbarram na barreira idiomática. Há algum tipo de discussão sobre o ensino de línguas entre as estratégias de internacionalização? Além disso, como enxerga o nosso campo do ponto de vista dos periódicos e o papel que eles atualmente desempenham na consolidação da área?

Embora a internacionalização seja desejável e possa acontecer em qualquer programa, até agora ela prevalece nos programas de excelência. Para além dos indicadores óbvios de produção intelectual, é entendida como a exposição do conhecimento à crítica internacional. E aí existe a barreira da língua. Os livros de história do Brasil são certamente mais difíceis de publicar no exterior. Mas esse é um aspecto da expressão propriamente material dessa produção. Não significa que não haja uma ambiência internacional na qual esse livro foi produzido. Há especificidades inegáveis da área da história, sendo a mais óbvia esse recorte nacional. Mas é também sintoma de internacionalização que um especialista estrangeiro em história do Brasil procure um programa daqui para publicar seu artigo em português.

Temos de dizer para a Capes - e não o inverso - o que nós consideramos internacionalização. Eu chamei atenção para nossas especificidades. Eles receberam bem: "Ótimo. Então demonstrem objetivamente que um livro em português foi produzido em um ambiente internacionalizado e ele vai ser avaliado como tal". Não há nenhuma resistência a isso. Existem critérios que cada área estabelece em um documento e que, uma vez aprovados, se tornam a regra da Capes para aquela área específica.

Vejam o caso do Programa de História Social da USP, nosso programa mais internacionalizado. Ele fomenta uma ambiência internacional: a convivência e o intercâmbio constante com pares estrangeiros, que muitas vezes vão à universidade para avaliar e discutir projetos, inclusive em português, que às vezes aprendem. É claro que os livros traduzidos em língua estrangeira e publicados no exterior são mais obviamente internacionais, mas as comissões de área nos últimos três triênios têm dado muita atenção ao fato de que a dimensão internacional do programa também se expressa no potencial de atração de seus professores para os especialistas em história do Brasil que estão no exterior. Não são muitos, mas existem. É uma exigência para os programas progredirem para as notas seis e sete, porque esses são programas considerados equivalentes aos dos grandes centros internacionais. Mas há iniciativas de internacionalização nos programas de nota quatro e cinco.

No tocante à multiplicação de periódicos, é uma realidade decorrente em grande medida da ideia de que todo programa de pós-graduação tem de ter sua publicação. Assim, acabam surgindo revistas de história com nenhuma expressão acadêmica: eventualmente até publicam artigos de boa qualidade, mas não circulam e são pouco acessadas quando são eletrônicas. Logo, algumas dessas revistas estão enfrentando problemas de captação de artigos, de completar números, de periodicidade, de financiamento etc. Talvez fosse desejável uma atuação interinstitucional que resultasse na fusão de periódicos, para que possam adquirir mais visibilidade.

Não há nenhum favorecimento no sentido de se publicar mais artigos ou mais livros. No último triênio houve uma produção muito grande de coletâneas pouco densas. Coletâneas que são, na verdade, resultado de eventos. Isso é resultante do produtivismo. 
Agora, com o estabelecimento dos pontos atribuídos aos livros, juntamente com a pontuação que já era dada aos artigos, adotamos um parâmetro diferente. Muitos programas estão privilegiando a pontuação como estratégia de planejamento ou como regra de credenciamento. Não importa que no triênio você publique um artigo, um livro ou um capítulo. Importa que você atinja a pontuação média, por exemplo, do seu estrato. Qual é a média da pontuação dos programas nota cinco? Hoje é possível responder a essa pergunta. Até a avaliação passada não era, porque ninguém tinha feito. Esse é um bom parâmetro de credenciamento.

Então, jamais houve essa orientação de supervalorização de artigos ou de capítulos ou de livros. O que ocorreu foi que os recursos do Proex [Programa de Excelência Acadêmica] e Proap [Programa de Apoio à Pós-graduação] para os programas notas cinco, seis e sete fizeram com que eles optassem por produzir muitas coletâneas com base em eventos. Temos uma verdadeira coletânea quando uma liderança intelectual de uma determinada especialidade temática ou dois ou três - convida outros autores referenciais daquela área a fazer uma reflexão sobre aquela problemática. Algumas são ótimas, outras não. O mais importante é que temos essa expressão da produção em termos de pontuação. E, portanto, se determinado programa quer manter sua pontuação ou progredir, tem de mirar essa pontuação independentemente de ela se expressar em artigos ou livros.

A questão da internacionalização e do aprendizado de línguas estrangeiras tem sido muito discutida na Capes, até porque várias áreas ligadas ao programa Ciência sem Fronteiras estão lidando com problemas relacionados a isso. A Capes começou a oferecer curso de inglês para quem fez o Enem [Exame Nacional do Ensino Médio]. É um curso bem interessante, produzido pelo Discovery. As ciências sociais e humanas também passaram a ter acesso ao curso. As embaixadas francesa e italiana prometeram oferecer cursos em seus respectivos idiomas.

Quero acoplar ao ensino de língua estrangeira um programa de fomento à história não brasileira que provisoriamente chamo de "História sem Fronteiras". Pretendo discutir com os praticantes dessas modalidades de história um formato adequado, debatendo também sobre o fomento ao "mestrado-sanduíche", ou seja, possibilitar que o mestrando possa fazer parte de sua formação no exterior, como o doutorando. O mestrado pode contribuir para a formação de pessoal na história não brasileira.

O que se espera de um aluno em termos de formação, quando sai do mestrado? Parece haver uma indefinição da área de história em relação a isso.

Muitas áreas veem o mestrado como etapa que poderia até ser eliminada. Em algumas delas, a tese de doutorado deu lugar à obrigação de publicar determinado número de artigos. Isso não funciona para nossa área. Para a história e as demais ciências humanas e sociais, é consenso que o mestrado é fundamental.

Não vejo problemas em haver heterogeneidade de diretrizes, porque diz respeito às peculiaridades de cada área. Para a informática, por exemplo, a publicação em livros não é interessante, pois o dinamismo na inovação é muito grande. Eles têm o Qualis² Eventos, já

\footnotetext{
${ }^{2}$ Qualis é o conjunto de procedimentos utilizados pela Capes para estratificação da qualidade da produção intelectual dos programas de pós-graduação (ver http://www.capes.gov.br/avaliacao/instrumentos-de-apoio/ classificacao-da-producao-intelectual).
} 
que incluir trabalhos em eventos reconhecidos da área é muito difícil. A peculiaridade de nossa área diz respeito à necessidade de erudição na formação, que o mestrado possibilita.

Diante da formação insuficiente dos recém-saídos da graduação, alguns programas têm ampliado o número de disciplinas no mestrado. Não sei se é a melhor solução, mas com certeza é um sintoma dessa crise. É essencial revalorizar o mestrado como um momento em que o aluno aprende a fazer uma pesquisa profissional, não necessariamente original, mas que demanda um controle de técnicas, métodos e teorias, inclusive para demonstrar a vocação para esse tipo de atividade. Nesse sentido não se distingue muito do doutorado. Muitas vezes as teses - assim como as dissertações, que às vezes são miniteses - também representam exercícios empíricos não originais de produção. Certamente há aí um problema entre tantos outros, como o da especialização precoce e dessa formação acelerada. Para revalorizar o mestrado talvez seja necessário rever o tempo de titulação; talvez a ampliação das disciplinas num mestrado mais formativo, quiçá a própria dimensão da dissertação. Teses e dissertações não são mais trabalhos terminais que coroam uma carreira. De qualquer forma, essas ideias precisam ser discutidas.

Uma alternativa talvez seja apresentada surpreendentemente pelos mestrados profissionais, que não exigem necessariamente uma dissertação acadêmica como produto final. Pode ser uma produção técnica, material didático, reflexão sobre fontes, o que for, desde que acompanhado de uma reflexão crítica. Isso talvez nos permita pensar de maneira mais flexível o próprio produto final do mestrado. Nosso modelo de disciplinas, qualificação no segundo ano, reformulação do projeto e apresentação da dissertação em dois anos é inviável.

Como você avalia o problema dos pareceres, procedimentos que serviram para certificar a maturidade da área e que requerem a aplicação de critérios objetivos?

A questão das revistas é fundamental, e o problema dos pareceres, dramático. Vivo isso com os pareceres para solicitações de bolsa para doutorado completo ou parcial no exterior. Dois pareceristas avaliam os pedidos para o coordenador de área, que a partir daí aprova ou não a concessão da bolsa. Em geral, com boas exceções, os pareceres são muito frágeis. No caso das revistas, os editores têm de fazer uma indução. Noto que muitas vezes eles ficam felizes apenas por receber um retorno dos pedidos de parecer. Essa é uma grande fragilidade da nossa área de história, em contraste com o cenário internacional. Mesmo as revistas mais qualificadas muitas vezes trabalham com pareceres muito frágeis e têm problema de retorno nas solicitações de avaliação. É algo que fragiliza a própria qualificação dos periódicos. Depende dos editores estabelecer procedimentos para recusar pareceres superficiais. É uma questão de maturidade da nossa área, consolidar práticas e procedimentos que sejam qualificados, mais do que uma medida que passa pela Capes. Isso tem a ver também com o Qualis Tecnológico que muitas áreas já estabeleceram devido à necessidade de avaliar a produção técnica. Funciona de forma semelhante à do Qualis Periódicos e do chamado Qualis Livros. A emissão de pareceres pode ser incluída aí. É um procedimento laborioso, que demanda cuidado. Algumas revistas, sobretudo as mais bem pontuadas, poderiam atestar as pessoas que colaboraram concedendo bons pareceres. Poderia ser um critério para o nosso Qualis Tecnológico. 
Parece haver um ruído na relação do conhecimento histórico com as demandas sociais, que muitas vezes se restringem a solicitações de cronologias e curiosidades. Como podemos mostrar que nosso ofício é mais amplo do que isso e demonstrar nosso potencial de atuação mediante a sociedade?

A demanda social é grande, mas pouco qualificada. De fato querem nossa assessoria sobre cronologias, detalhes e curiosidades históricas. Mas isso também depende de nossa atuação. Quantos pesquisadores acadêmicos têm coragem de ir a público? Temos de entrar na disputa, ligada a questões de memória e do tempo presente, mas que também ocorre em outras áreas. O pesquisador acadêmico é quem está qualificado para dar conta dessa demanda, mas para isso ele precisa se despir um pouco da capa púrpura e participar da disputa por memórias, discursos, lutar contra os estereótipos e clichês. É algo que depende de nós mesmos e da maturidade da área.

Não há uma distorção no modo como se pensa a história regional? A historiografia que pretende abrangência nacional, mas que é produzida basicamente no eixo Rio-São Paulo, também não seria em suas bases local e regional?

Há o problema de que às vezes o que é identificado como história regional na verdade é a história de um lugar. A história regional é uma especialidade muito sofisticada, que demanda o equacionamento temporal-espacial. Ela pode até abarcar espaços não contíguos. É muito perceptível, em termos de densidade de conhecimento, a diferença da verdadeira história regional de uma história paroquialista. Sem desconsiderar o fato de que a história local é relevante por fortalecer trabalhos de constituição de acervos, de memórias. Mas acho que não se deve confundir a efetiva história regional com essas abordagens localistas.

A graduação em história não estaria privilegiando a formação para a academia em detrimento da licenciatura, daí resultando as distorções que você mencionou de uma especialização precoce?

A formação em licenciatura é uma das maiores fragilidades nos cursos universitários de história. As faculdades de educação são rotinizadas por perspectivas pedagógicas e didáticas em sua maioria rudimentares. Outro problema recai sobre a negligência dos docentes dos cursos de graduação, que oferecem a mesma disciplina para o bacharelando ou licenciando como se não houvesse distinção. Mas isso está fora da minha órbita de ação como coordenador da área da Capes. Defendo reformas curriculares que acabem com os recortes tradicionalistas e privilegiem um enfoque triplo de natureza historiográfica, teórica e de ensino.

A exigência de maior produtividade a fim de ganhar mais verbas não favorece uma visão taylorista do conhecimento histórico?

Não há nenhuma diretriz de publicar cada vez mais. Pelo contrário, minha orientação é publicar menos e com mais qualidade. Sempre disse isso nas várias visitas que fiz a programas de pós-graduação, mesmo quando era apenas membro da Comissão [de Avaliação da Área de História] na gestão da Raquel Glezer. No caso das coletâneas, por exemplo, investiu-se nelas para aumentar o número de publicações, mas muitas não têm densidade. Outra coisa é publicar melhor, produzir conhecimento relevante. Um professor de pósgraduação que publique no triênio poucos itens, em veículos qualificados, já apresenta 
um desempenho muito bom. Então, a ideia produtivista de que é preciso publicar cada vez mais não é orientação da Capes, nem da coordenação da área de história. O preparo das coletâneas demanda energia, sendo que talvez valha mais a pena investir num artigo mais denso. O governo brasileiro que financia a pós-graduação com dinheiro público espera como contrapartida que a produção intelectual dos programas seja significativa enquanto conhecimento relevante e que forme bons mestres e doutores. A única maneira de avaliar isso é por meio dos pares. O Qualis Periódicos e o Qualis Livros foram formulados para isso. Não é uma matematização sem sentido, nem um produtivismo. É uma pontuação pactuada com a área. Nós combatemos mecanismos artificiais de ampliação da produção, como o excesso de coautorias observado nas outras áreas.

Como discutir questões pertinentes às revistas da área de história, como a periodicidade, em fóruns como Capes e Scielo? Em que medida experiências de revistas regionais, bem-sucedidas em termos de reconhecimento e internacionalização, como o Boletim do Museu Goeldi, podem ser usadas para se pensar a história regional?

O Scielo é uma instituição que está sobrecarregada, por isso não consideramos tanto para a avaliação do Qualis da Capes se o periódico pertence ou não ao repositório. Existem várias formas de se avaliar a qualidade de uma revista. Quando alguns dos indexadores começam a não dar conta do recado, torna-se inviável. Ocorre algo semelhante com a bolsa de produtividade. Enquanto algumas áreas consideram o número de bolsistas de produtividade do CNPq elemento importante para a avaliação dos programas de pós-graduação, na história sabemos que há poucas bolsas, de modo que não dá para cobrar número elevado de bolsistas para conferir uma boa nota. Da mesma forma, não dá para exigir que o periódico esteja no Scielo para que ele seja pontuado.

Existem algumas iniciativas de fortalecimento dos periódicos. Inicialmente a Capes queria que cada área escolhesse dois periódicos para receber recursos. Impedimentos jurídicos bloquearam a medida. Mas há uma política constante. Há várias tendências, sobretudo de tradução e publicação em língua estrangeira, de procedimentos de pareceres etc. No caso da área de história, as últimas comissões envolvidas na atribuição de notas têm buscado aprimorar esses procedimentos no sentido de não cometer injustiças com revistas, por exemplo, com as publicadas fora do eixo Rio-São Paulo. No Brasil inteiro temos revistas que são muito qualificadas. A questão da história paroquialista e da pulverização de periódicos não passa por aí. Há uma série de revistas em estratos muito inferiores no Qualis, prejudicando a área como um todo. Talvez seja o caso de pensarmos estratégias, como a publicação interinstitucional ou fusão de periódicos. Há universidades que têm mais de um periódico na mesma área, que saem atrasados e disputam recursos. Algumas especialidades temáticas contêm vários periódicos pulverizados, que, se fossem reunidos, tornar-se-iam mais sólidos e expressivos. Essas questões esbarram em vaidades, disputas políticas e outros componentes alheios à avaliação da Capes, mas que são referentes à maturidade da área. Poderíamos tomar algumas medidas para aprimorá-la, atacando algumas fragilidades. Por exemplo, não temos sequer um indexador da área de história. 
Os periódicos podem ter seu ranqueamento alterado com o tempo? Se assim for, o planejamento individual em termos de pontos não fica comprometido pelas mudanças que podem ocorrer nessa classificação?

As notas do Qualis são atualizadas anualmente porque sempre temos de avaliar periódicos nos quais ninguém havia publicado até então e que por isso não tinham nota. Ocorre também que revistas que melhoram seu padrão conseguem recursos e publicam em língua estrangeira e por isso demandam aumento da nota, pedido que é avaliado pelo comitê responsável. É relativamente raro que uma revista B1 caia para B5. Apenas em casos extremos uma revista decresce dois níveis. Dificilmente há variações dramáticas. Portanto, dá para planejar. A vantagem é que a atualização dá chance para as revistas se aperfeiçoarem e melhorarem sua avaliação. Quero implementar agora para os livros. Não divulgávamos as notas individuais dos livros, apenas o número de obras classificadas nas respectivas categorias, mas agora fazemos. Minha ideia é possibilitar ao pesquisador que entre com recurso caso não concorde com a nota dada a seu livro. Na atualização dos dados, esse recurso poderá ser considerado, e a avaliação, revista. Isso dá mais segurança ao coletivo de pesquisadores e promove mais transparência.

Como a Capes enxerga atualmente a publicação de docentes em revistas ligadas aos próprios programas e instituições a que pertencem? Em alguns casos, a instituição dispõe de revistas de grande qualidade e visibilidade, mas na qual os pesquisadores não podem publicar por configurar endogenia.

Penalizar a endogenia, tanto de periódicos quanto de livros, foi uma decisão da coordenação da área porque havia excessos. As coletâneas, por exemplo, reuniam os trabalhos de todos os colegas do departamento para atender às exigências de produção, resultando num livro muito heterogêneo. Estabelecemos limites em torno de 30\%. Endogenia é um movimento do corpo de pesquisadores de só publicar ou publicar demasiadamente num veículo ao qual tenha acesso mais facilitado. Esse é um critério que não é da Capes, é universal. O debate sobre a endogenia surgiu para evitar meios potencialmente capazes de promover desvios e tendências destinadas a favorecer as notas. Não se deve esperar que apenas a coordenação da área defina isso. Precisamos pensar critérios que não favoreçam grupos que publiquem muito na própria revista, que façam coletâneas com todos os membros do programa ou que assinem trabalhos de seus orientandos.

Como avalia o posicionamento manifestado pela área de história em documento no qual afirma não ver com bons olhos a publicação de artigos em coautoria? Não considera problemática a equiparação de problemas de ordem moral - docentes que buscam aumentar a produtividade assinando trabalhos com orientandos - com a ideia de coautoria como expressão de uma colaboração efetiva entre autores?

O trabalho em coautoria é legítimo, seja ele com quem for. Mas tem de haver critérios para distinguir o que é um autêntico trabalho de coautoria do mero aproveitamento da mão de obra de orientandos. Tais critérios, entretanto, ainda não foram estabelecidos. É preciso que sejam pactuados pela área como um todo e não definidos pela coordenação da Capes. Não é difícil identificar distorções, como no caso de um mesmo professor que publica 
com diversos orientandos ou ex-orientandos num mesmo triênio. Se isso começa a ocorrer com muita frequência, temos de limitar.

No que se refere às discussões sobre os critérios para avaliação da área, conseguimos estabelecer um acordo de que não vai haver nenhuma mudança dramática a não ser que traga melhorias evidentes.

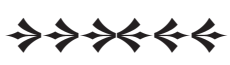

